\title{
Organizational Integration of the Information System Design Process*
}

\author{
Friedemann Reim \\ Fraunhofer-Institut für Arbeitswirtschaft und Organisation, \\ Nobelstr. $12 c, D-7000$ Stuttgart 80 \\ Phone: +49-711-9702339
}

\section{Subject Area: Information Systems Planning}

\begin{abstract}
Design and operation of a distributed information system have to consider a dynamic environment of requirements and opportunities. Full usage of the power of an information system can only be achieved through its integration into the various interrelated design and management activities in an enterprise. Simultaneously engineering the entire design process is recommended. ESPRIT project COMANDOS takes an adaptive approach for the design and management of distributed information systems that allows the original design of the infrastructure to be modified as experience is gained and as user requirements towards the operating environment change. One tool out of a set of required tools is described in detail: DISDES - a tool for organizational design.
\end{abstract}

\section{The Challenge for the Competitive Enterprise}

Many enterprises consider information systems as a critical success factor. The advent of distributed information systems even increases opportunities for an improved support of business activities. However, it certainly also increases risks for the enterprise since the design and the operation of such systems are rather complex tasks which involve important new issues.

The design of the information system has to provide for continuous adaptation of the system to the task supported, to the business processes and to the organizational structure as a whole. This clearly calls for a well-defined coupling between the organizational design tasks, driven for example by a business analyst, and the engineering of the information system itself.

In the field of industrial product development this coupling of interrelated, parallel design processes is called simultaneous engineering. For the information system design and its integration within an enterprise this simultaneous engineering paradigm needs to be adopted. Sequential, more or less independently performed design tasks will not be successful.

\footnotetext{
* This work has been partly supported by ESPRIT Project 2071 Construction and Management of Distributed Open Systems (COMANDOS)
} 
Simultaneous engineering leads to changes in the various tasks involved: Configuration instead of new program development: Developing new applications will consist primarily of configuration, and only marginally of programming (cf. Tsichritzis, Nierstrasz (1988)).

Integration instead of isolation: The integration of the organizational and the technical design processes will be crucial.

Cooperation instead of self-sufficiency: The simultaneous engineering paradigm will lead to new ways of cooperation between the various departments and also change the role of the department responsible for electronic data processing.

\section{The Distributed Information System Scenario}

The emergence of medium and large computer installations throughout the enterprise will lead to an increasing demand for distributed applications. Increasing decentralization through powerful workstations, however, will be accompanied by an organizational integration into business processes spanning the whole enterprise. Available technology will decrease the cost for carrying out operations remotely. This opens new opportunities for the integration among organizational units.

Distribution transparency of the underlying information system and of the application neither will be the solution to the challenge of distribution nor will it be an independent goal. Most difficulties associated with distribution would not vanish even given full distribution transparency. Problems are in fact present even in centralized, sequential information systems. They become more serious in a distributed system (cf. Mühlhäuser (1991)).

Frequently knowledge about the application structure and behaviour can help to provide an optimized distribution service or can help to determine the location of users relative to application entities. This knowledge needs to be used for the design and the configuration of the distributed information system.

Approaches to organizational design and to technical design of information systems often are oriented towards a life-cycle model putting most emphasis on the early stages. These approaches tend to neglect the use and operation of an information system after implementation. This is certainly inappropriate when one is concerned with its continuing performance over a long period of operation. Distribution makes this problem more serious since the design of a distributed system is more complex. In addition, the dynamics of such a distributed environment tend to increase. 
A distributed information system must be structurally responsive to changes in its environment and allow for a selective degree of distribution transparency.

\section{The Design Tasks}

Information system design often is viewed as a set of individual design processes. These processes differ in focus. They may take an organizational or a technical view. In distributed information systems also a specific view on security is recommended. Within each such process issues of an overall information processing strategy which, for instance, determines the desired degree of decentralization, have to be addressed. Based on this IP strategy issues of organizational structure, technology selection and its economy, installation and implementation have to be dealt with. The number of design alternatives is reduced when proceeding from IP strategy selection to operation of the system (cf. Figure 1).

Three types of design tasks are distinguished here: organizational management, configuration management and security management.

Organizational management is responsible for the appropriate design of the organizational structure, i.e. its engineering, which in turn determines the required functionality of the distributed information system.

The configuration management consists of hardware configuration and system administration which is more oriented to logical concepts than physical components. A system administration model comprises persons, users, groups, accounts, hosts, and home directories.

Security management has to achieve and enforce integrity, availability and confidentiality of information. For distributed information systems availability of information is a crucial point. Risks due to failure of system components have to be analyzed and evaluated.

All these design processes are strongly interrelated. A simultaneous engineering approach to information systems design requires a conceptual and technical integration among these processes.

Several methods and tools exist that support the design tasks for distributed information systems. However, no tool or set of tools covering the range from organizational design to configuration management exists that is integrated into the distributed information system itself, thus capable of fully exploiting its power (cf. Ness, Reim, Meitner and Niemeier (1986)). 
Strategy of the company
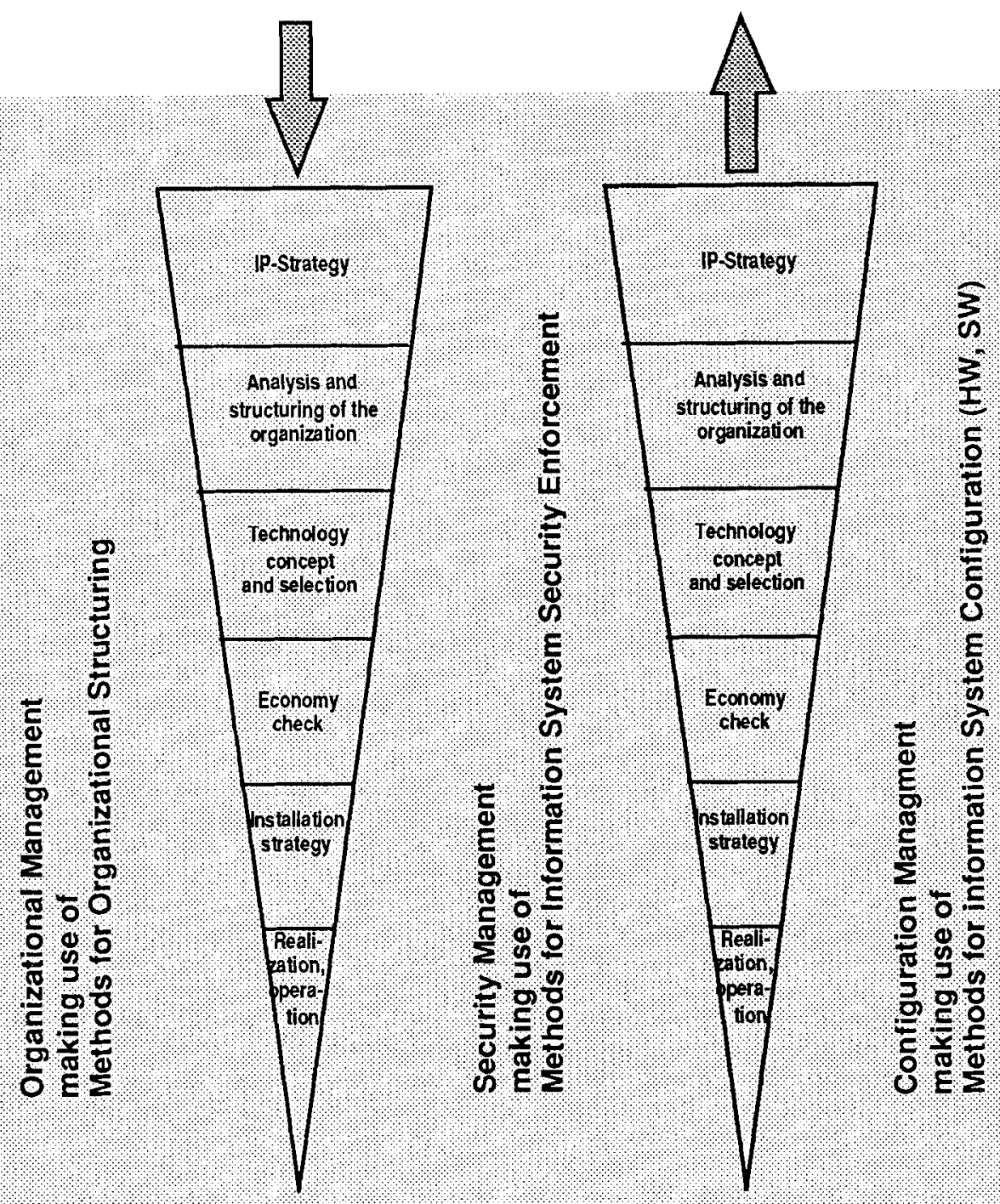

Figure 1: Major Issues of Integrated Information System Management

ESPRIT Project 2071 (Construction and Management of Distributed Open Systems, COMANDOS) provides an infrastructure and tools to construct and manage distributed information systems. It comprises a set of tools supporting management decisions on the general design as well as administration activities that transform these decisions into an operational distributed system (cf. Balter (1989)). The tools are coupled, thus integra- 
ting the various design processes. The basic management tasks supported by computer based tools are depicted in Figure 2.

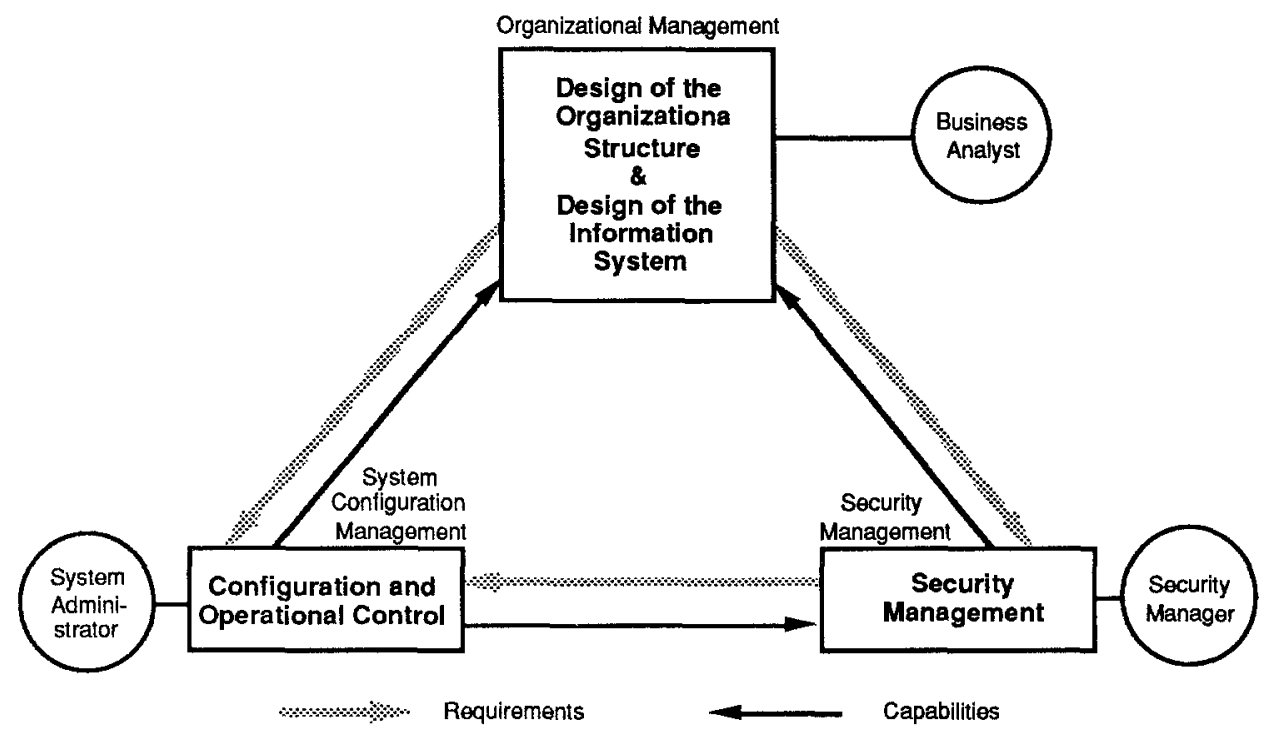

Figure 2: Basic Management Tasks Addressed in the COMANDOS Project

Two types of relationships exist between the management tasks: requirements and capabilities. The posing of the requirements sets the goals to be achieved by the other basic task and determines the major dependency direction in the hierarchy of the basic tasks. However, dependency is bidirectional because the basic management task posing a requirement must be informed about the capabilities of the other basic tasks in order to pose realistic requirements and to fully use the potential.

The organizational engineering approach of COMANDOS is described here. It refines the upper box of Figure 2. Other tools developed in the project are described in Reim, Meitner (1991).

\section{Example: The Organizational Engineering Tool}

The organizational design is based on a process-oriented view on office activities (cf. Bracchi, Pernici (1984)). Activities and processes are the basic elements for modelling the flow of office tasks. Actor-oriented features also are represented, thus allowing the modeling of capacity aspects. Figure 3 shows the model entities and their relations.

Activities are atomic tasks carried out by a position without interruption. Processes are sequences of a number of possibly parallel activities or (sub-) processes with a unique start and a unique end activity. Positions are the only organizational units capable of carrying out activities; they are 
held by humans. Relationships may exist between the entities. The Control relation represents the control flow between activities. Supervise poses responsibilities for carrying out activities upon positions.

The organizational model furthermore comprises Organizational Groups and Persons. In order to enable the configuration of a distributed information system, the above entities are conceptually related to the concepts for describing the distributed information system. This is achieved by typing the activities. The Activity Types - they also could be called activity classes - represent a classification of office work. Modelling at present is restricted software. Every activity type poses requirements (Requires relation) upon the software to be installed. Since this software provides a specific functionality, it is called Function Software. Every User known to the information system Has A User Environment which consists of a set of function software.

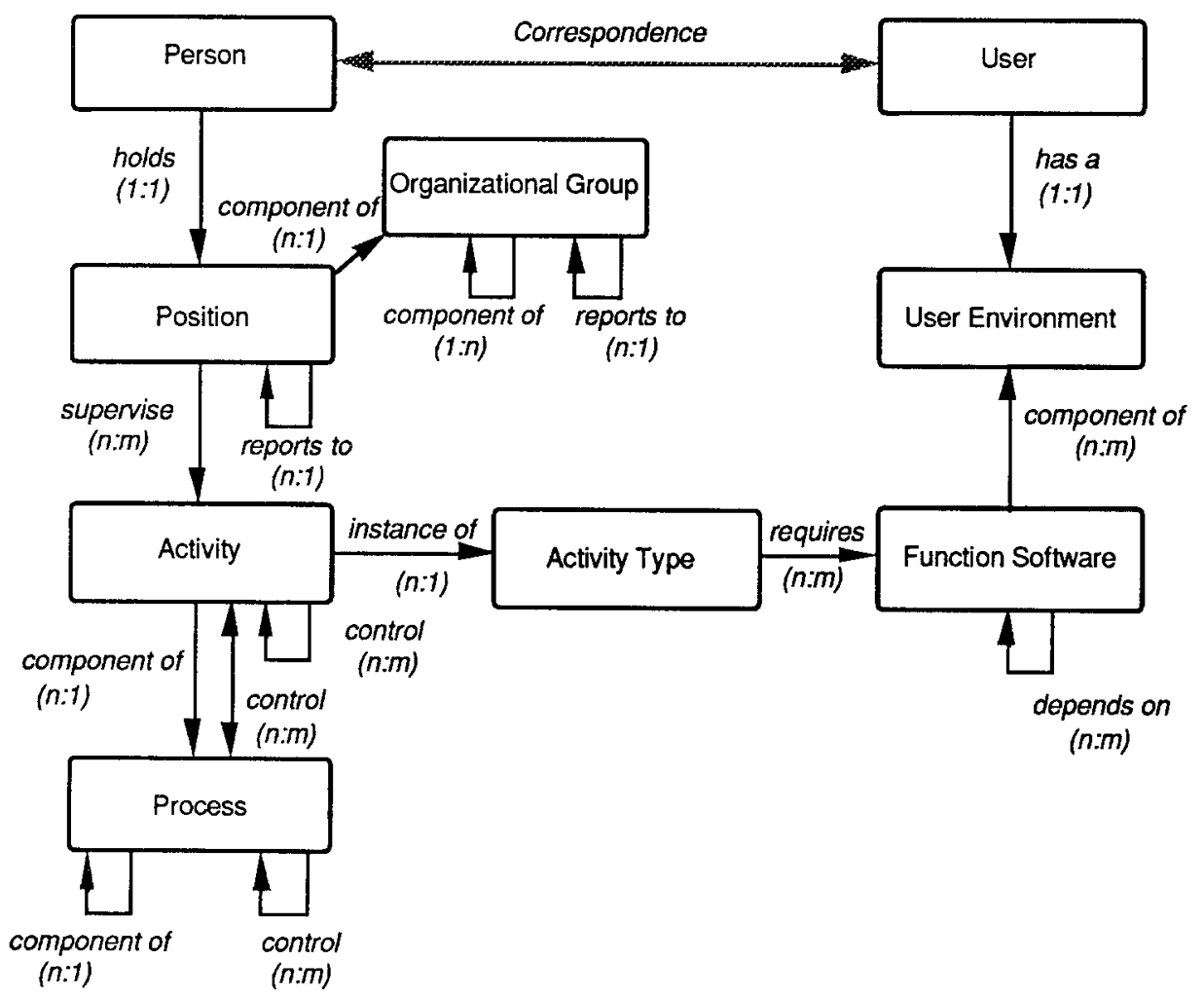

Figure 3: Model Elements of the Organizational and Information System Model

The modell represents the conceptual core of DISDES. Distributed Information Systems DESigner (DISDES) is a decision support system for the organizational designer / business analyst. His responsibilities include the 
selection of the information system components appropriate to support the office tasks.

DISDES has been implemented on a workstation. Figure 4 shows the logical structure of the tool.

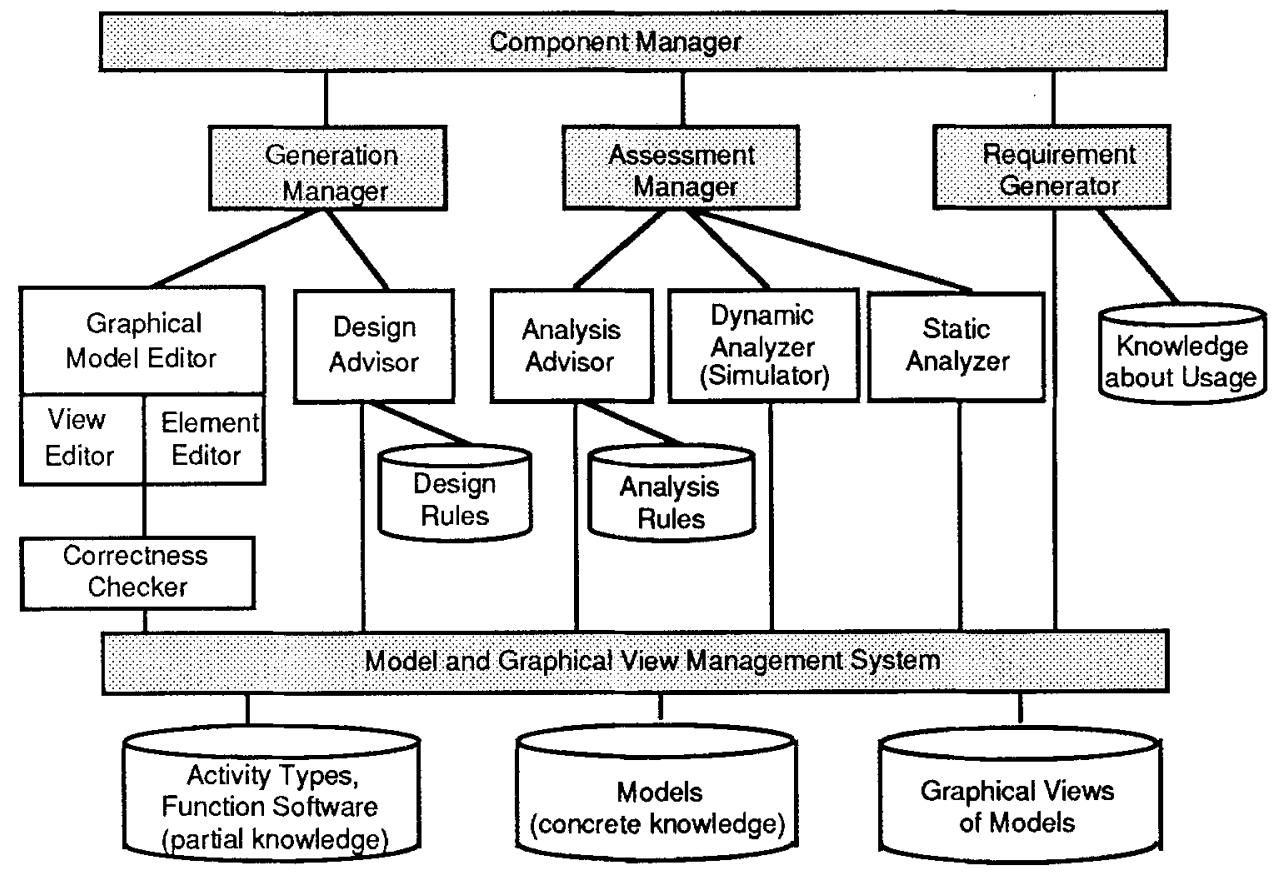

Figure 4: Architecture of the DISDES Tool

On the top level the organizational designer / business analyst interacts with the component manager. It allows to switch between generating solutions, assessing solutions, and automatically deriving requirements for the distributed infromation system.

The generation components support the organizational designer in understanding the problem, modeling, inventing and developing a better office and information system design. Representation and manipulation of an office model is supported, and active advise is given on how to carry out the design. The tool components for generating design solutions are the generation manager comprising a graphical model editor and an element editor, a correctness checker, and a design advisor which possesses a set of rules representing general design knowledge.

The assessment components support the organizational designer in testing and evaluating the solutions generated with respect to the goals of the design. They provide information about the quality of the design of the 
office and its information system by analyzing the model. Several ways of analyzing the model support a variety of possible assessment goals. Depending on the kind of analysis, different features of the model or different effects of its simulation are accounted for. The organizational designer then is supported in interpreting these results. The tool components for assessing solutions are the assessment manager, the dynamic analyzer, the static analyzer and the analysis advisor providing support for result interpretation.

The model and graphical view management system is the underlying storage system for the logical office and information system models.

The decision support tool DISDES supports the following tasks:

- Representation and generation of a model of an office and its distributed information system:

The user of the tool benefits from the graphical, interactive user interface of DISDES. An example of the usage of DISDES is shown in Figure 5. Cut and paste features ease the generation of alternative solutions.

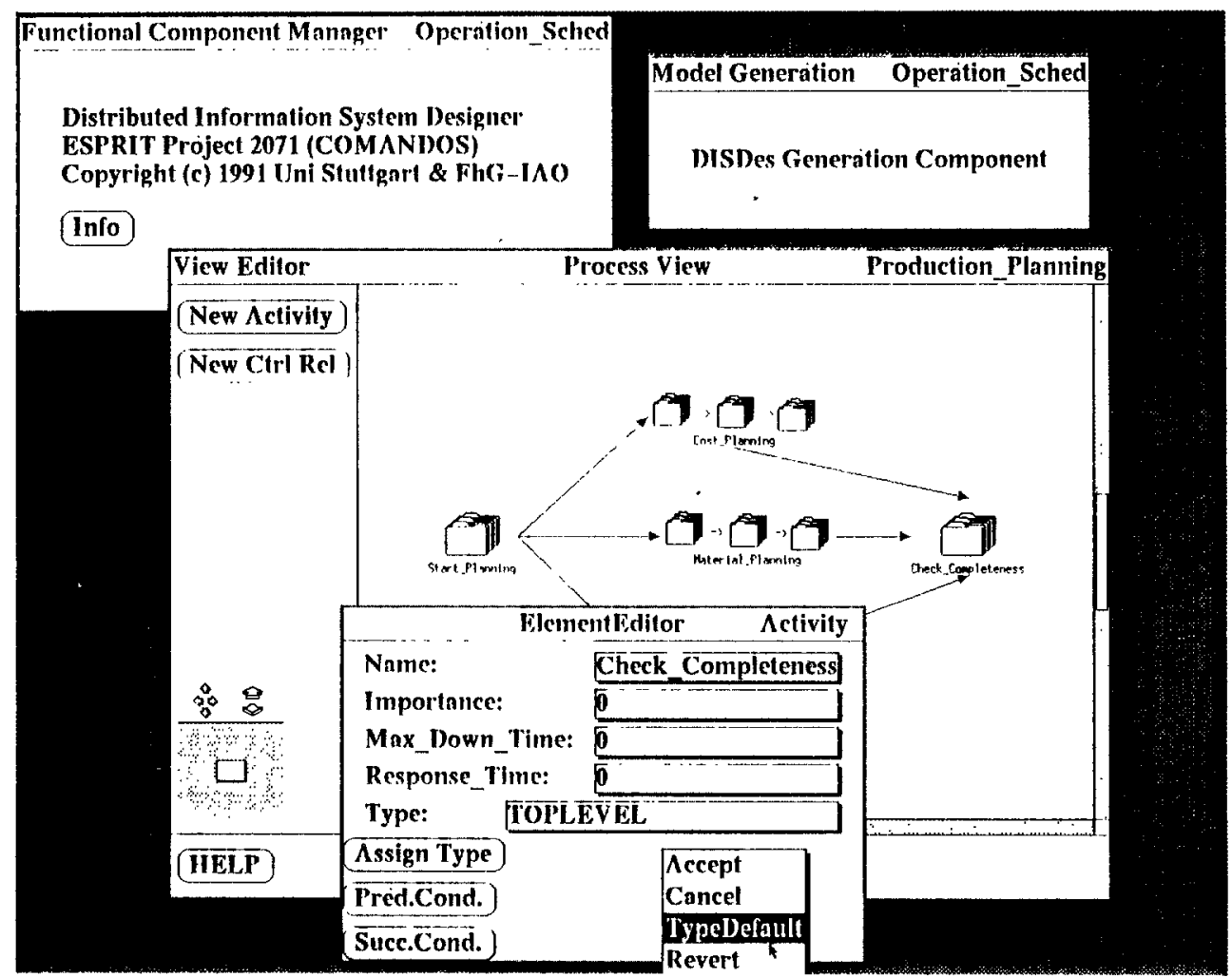

Figure 5: Screen dump showing usage of DISDES. 
Figure 5 shows the generation of the model for the organizational design of the "production planning" Process in an enterprise. For the enterprise "production planning" is a generic procedure that has to be carried out frequently. It consists of various sub-processes, among them "cost planning" and "material planning". "Start planning" and "check completness" are atomic Activities. Arrows represent Control relations. Every element including the relations can be further described by attributes. The element editor is used to assign values. In Figure 5 the importance of the newly generated "check completeness"' activity is rated. Requirements for its maximally acceptable time of unavailability (down time) and requirements for response time can be stated. At creation time all values are set to " 0 ".

The decision support tool DISDES furthermore supports:

- Assessment of alternative design solutions: The assessment components of DISDES allow the evaluation of the performance of proposed alternative solutions to a distributed information system design problem. The dynamic analysis is based upon a discrete simulation on the office model.

The design of the organizational structure and of the distributed information system has no direct coupling to the operational system. Coupling to the operational information system is achieved through the Requirement Generator. This component generates a specification of the required functionalities and gives hints on how to configure the distributed information system, i.e. by identifying the location of primary usage of software and data. Thus knowledge available during the organizational design process is made available directly to configuration management. The underlying model (Figure 3) allows for a selective level of detail - with respect to organizational as well as information system aspects.

In order to achieve this coupling the decision support tool DISDES supports the following task:

- Derivation of the required information system functionality including hints about expected usage patterns: To obtain requirements, DISDES needs tayloring to the specific enterprise. The function software components available within the enterprise need to be loaded into the the model and graphical view management system of DISDES (cf. Figure 4). This activity has to be carried out only once. When additional software is purchased this software component has to be added.

In a similar way, a set of activities types has to be loaded into the the model and graphical view management system. The activity types represent a classification which is used to reduce the otherwise huge number of individual activities in an enterprise. It eases the assignment of software to activities. In principle, these activity types are 
not necessary. However, without the types assigning function software to activities would be a prohibitively costly task.

In accordance with the CIM-OSA reference model this kind of information is called partial knowledge (cf. Stotko (1989)).

Figure 6 depicts the steps necessary to obtain requirements derived from the organization modell (cf. Reim (1992)).
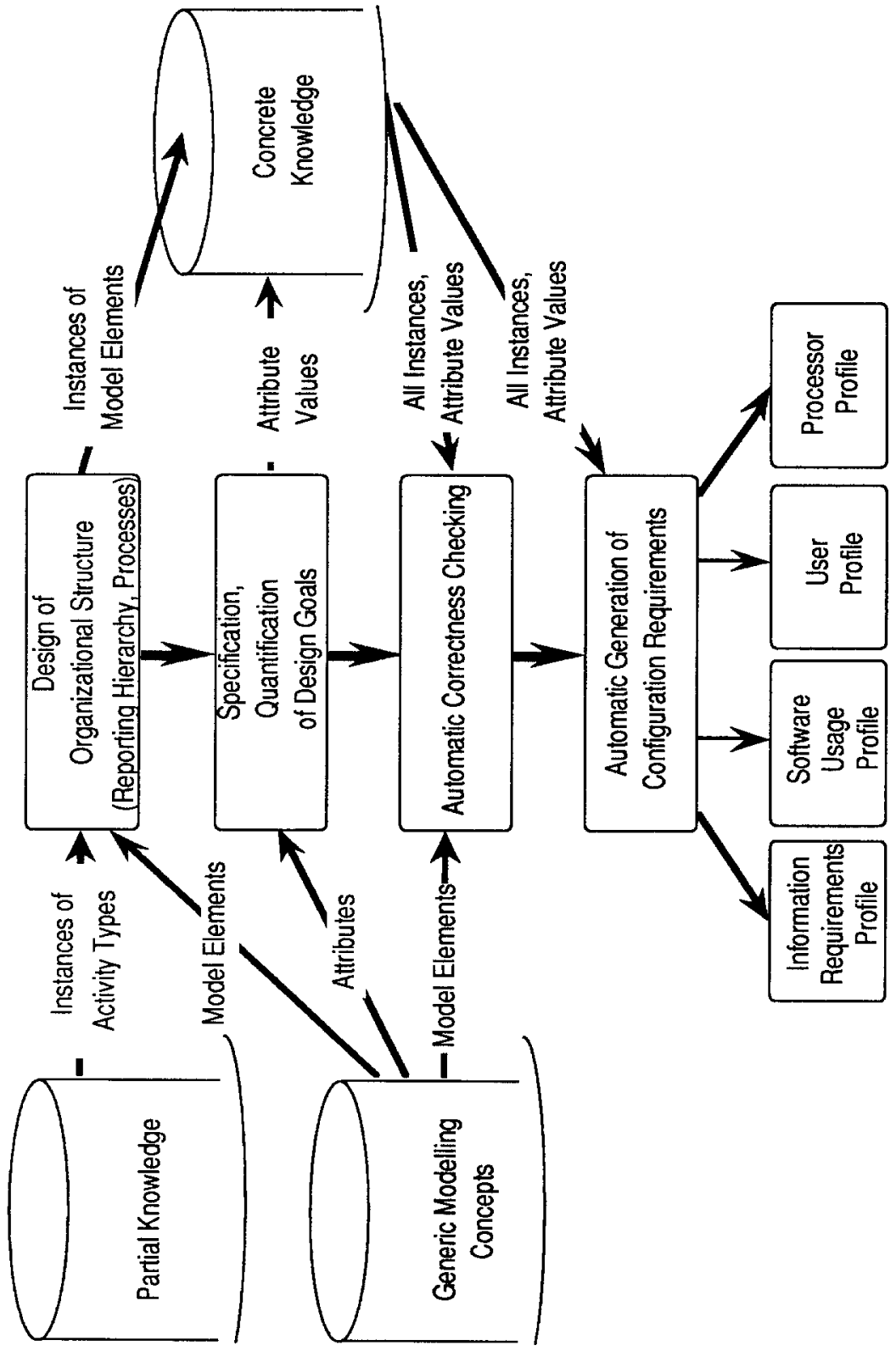

Figure 6: Necessary steps to generate requirements by using DISDES 
Figure 7 summarizes the content of the various profiles generated by the requirement generator.

\begin{tabular}{|l|l|}
\hline Information Requirements Profile & $\begin{array}{l}\text { How frequently and at which loca- } \\
\text { tion are the data accessed / up- } \\
\text { dated? }\end{array}$ \\
\hline Software Usage Profile & $\begin{array}{l}\text { What is the intensity and the loca- } \\
\text { tion of software usage? }\end{array}$ \\
\hline User Profile & $\begin{array}{l}\text { What users have to be installed? } \\
\text { What access rights do they need? }\end{array}$ \\
\hline Processor Profile & $\begin{array}{l}\text { What proceesing power is needed } \\
\text { in order to guarantee response } \\
\text { times? }\end{array}$ \\
\hline
\end{tabular}

Figure 7: Requirements generated by DISDES

Requirements for security management are passed in a similar way.

\section{$5 \quad$ First Experiences}

First practical experiences with DISDES have been gained. In the following section the expert evaluation of one major application is described.

The tool has been applied for the organizational and technical design of the distributed information system of the service organization of a car manufacturer. Along with cost and quality, customer service more and more becomes a critical factor for their market success. The "computer aided service" supported by the service network will be part of an overall network that integrates suppliers and dealers with the manufacturer. The supplier network ensures just-in-time delivery of components and material. An internal network closely links research and development staff. Shorter product life cicles force a much closer integration with research and development of the suppliers. The sales organization offering several additional services such as insurance and financing needs direct communication with the manufacturer. The distribution network also is expected to improve the training capabilities. Figure 8 shows the envisaged network. 


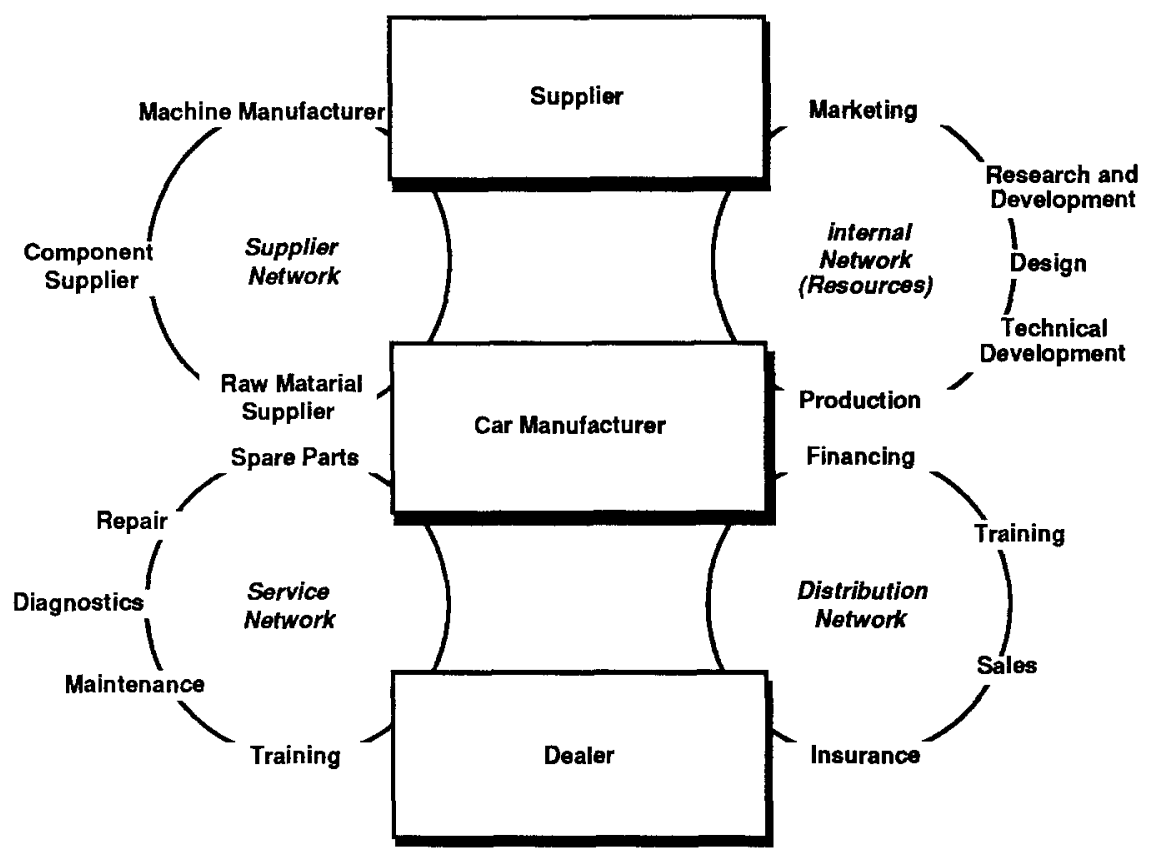

Figure 8: Integrated Network of a Car Manufacturer

A major German car manufacturer explores new ways for providing an improved service quality. The communication infrastructure for the emerging computer aided service relies on the wide area broadband network which currently is in a field test by the German PTT. It allows the local car dealer to use applications such as "online diagnostics supported by the central product development staff" or "online transmission of teaching material to the local mechanician".

Due to the capabilities of the communication system an entirely modified configuration of the distributed information system has been designed. Experts who manually, i.e. without computer supported tools, did accomplish this complex design task have been asked to "re-design" the service organization and its information system using the DISDES tool. They were then asked to compare the two design procedures and the results produced.

This comparative evaluation requires an in-depth knowledge of the service organization and of the information system. The number of experts available was very small. The results obtained represent a qualitative evaluation of DISDES. It was not possible to carry out a statistical survey.

Figure 9 sumarizes the expert opinions upon the effort required for applying DISDES. 


\begin{tabular}{|l|c|c|c||c|}
\hline Criteria & \multicolumn{3}{|c||}{$\begin{array}{l}\text { Comparative Evaluation: } \\
\text { DISDES tool vs. manual design }\end{array}$} & \\
\hline & $\begin{array}{c}\text { Expert } \\
1\end{array}$ & $\begin{array}{c}\text { Expert } \\
2\end{array}$ & $\begin{array}{c}\text { Expert } \\
3\end{array}$ & \\
\hline $\begin{array}{l}\text { Turnaround time for } \\
\text { entire design process }\end{array}$ & 0 & + & + & - No or minor improvements \\
\hline $\begin{array}{l}\text { Number of design } \\
\text { alternatives considered }\end{array}$ & + & + & + & - Significant increase \\
\hline $\begin{array}{l}\text { Clearness of design } \\
\text { documentation }\end{array}$ & + & + & 0 & - Significant improvement \\
\hline $\begin{array}{l}\text { Effort required to keep } \\
\text { model up to date }\end{array}$ & + & - & + & - Improvement \\
\hline
\end{tabular}

Changes observed by the experts after using DISDES:

+ Improvement $\mathrm{O}$ unchanged - Deterioration

Figure 9: Evaluation of the Effort Required for Applying the Computer Aided Tool DISDES Compared to the Traditional, Manual Design

According to the experts, the turnaround time for the entire design process only showed minor, insignificant improvements. However, the number of design alternatives that have been considered during this time considerably increased. Also the tool clearly led to a better documentation. Modifications and adaptations of a design are more simple. Expert 2 in this case assumed that updates and, in particular, their documentation only occur in longer time intervalls. Availability of a tool might lead to more frequent modifications and consequently to an increased effort. In subsequent discussions he - as all the other experts - agreed that this results in a more appropriate, better design for the enterprise.

Figure 10 summarizes the expert opinions on the quality of the results.

Expert judgements for the quality of results achieved when using the DISDES tool show strong coherence. The level of detail has been increased for the organizational as well as for the technical aspects. Organizational aspects refer to the organizational structure which had to be modified to make optimal usage of the technical capabilities available. Technical aspects represent the requirements passed to the system administrator who has to configure the information system accordingly. 


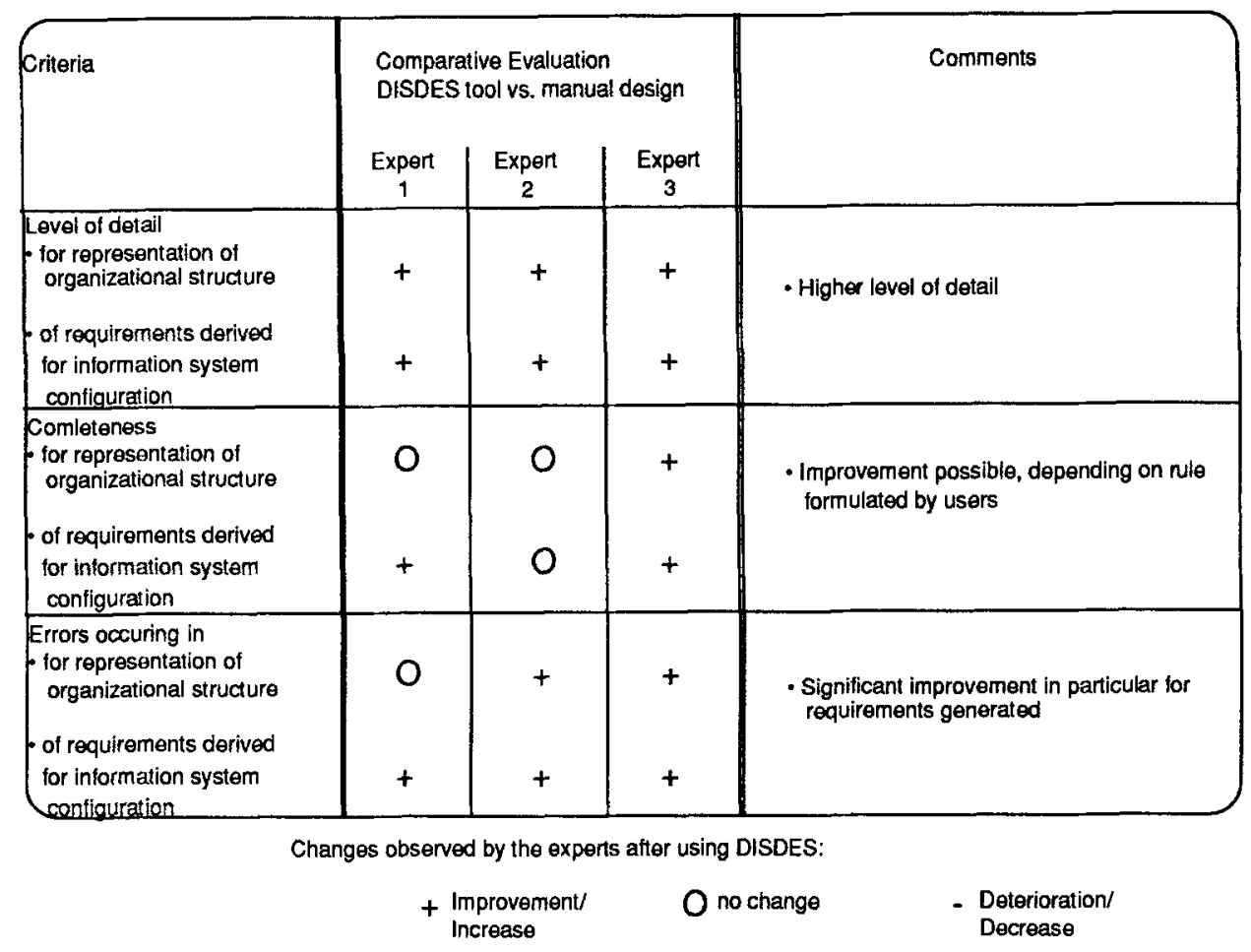

Figure 10: Evaluation of the Results Produced with the Computer Aided Tool DISDES Compared to the Results of the Traditional, Manual Design Process

DISDES enforces the completeness. It also helps to detect and eliminate errors in the design. In summary, first practical experiences with DISDES are promising.

\section{Status of Tool Implementation}

Prototypes of several tools - not only of DISDES itself - and for services for system observation and control have been implemented on top of UNIX machines connected via Ethernet (Sun 3/50, Sun 3/60, Sun SPARCstation, Vax station II) and on IBM PC under MS/DOS (cf. Reim and Meitner (1991)). C++ has been chosen as the implementation language. For the graphical interface of the tools $\mathrm{X}$-Windows and InterViews have been selected. A general and reusable structure of classes for the maintenance of object has been developed.

Research and development efforts currently address the conceptual and functional integration of available CASE tools. A major focus also deals 
with ways of supporting the design and operational control of business procedures.

\section{$7 \quad$ References}

Balter, R. (1989), Construction and Management of Distributed Office Systems - Achievements and Future Trends, in: ESPRIT'89, Proceedings of the 6th Annual ESPRIT Conference, Commission of the European Communities (Ed.), pp. 47-58

Bracchi, G.; Pernici, B. (1984), The Design Requirements of Office Systems, in: ACM Transactions on Office Information Systems 2 (1984) Nr. 2, pp. 151-170.

Mühlhäuser, M. (1991), Software Engineering in Distributed Systems Approaches and Issues, in: The DOCASE Project - Part 2: Selection of Publications- Version 1.0, 1991, Digital - Campusbased Engineering Center, Karlsruhe.

Ness, A., F. Reim, H. Meitner and J. Niemeier (1986), Decision Support System for Planning and Design of Distributed Office Systems, Deliverable FHG-D1-T1.1-860829 of ESPRIT Project 834 (COMANDOS), Universität Stuttgart and Fraunhofer-Institut für Arbeitswirtschaft und Organisation, Stuttgart, August 1986

Reim, F. und H. Meitner (1991): A Toolset for Administration and Management of Distributed Information Systems, in: Human Aspects in Computing: Design and Use of Interactive Systems and Work with Terminals/ Ed. by H.-J. Bullinger, Elsevier Science Publishers, Amsterdam, 1991, pp 374-378.

Reim, F. (1992): Entwicklung eines Verfahrens zur rechnerunterstützten Gestaltung verteilter Informationssysteme, PhD Dissertation, Universität Stuttgart, 1992.

Stotko, E. C. (1989), CIM-OSA, in: CIM Management 5 (1989) No. 1, pp. 9-15.

Tsichritzis, D.C.; Nierstrasz, O., Application Development Using Objects, in: Information Technology for Organisational Systems/ Ed. by H.-J. Bullinger; E.N. Protonotarius; D. Bouwhuis; F. Reim. Amsterdam, North-Holland, 1988, pp. 15-23 